\title{
Health Expenditure and Child Health Outcome in West Africa
}

\author{
Olufemi Solomon Olatunde ${ }^{1}$ \\ Abayomi A. Adebayo ${ }^{2}$ \\ Fisayo Fagbemi ${ }^{3}$
}

\section{Department of Economics, Obafemi Awolowo University, Ile-Ife, Nigeria. Email: olufemi.olatunde@gmail.com \\ ${ }^{s}$ M.Sc. Obafemi Awolowo University, Ile-Ife, Osun State, Nigeria. \\ ${ }^{s}$ Email:fisay4real@yahoo.com}

Licensed:

This work is licensed under a Creative Commons Attribution 4.0 License.

Keywords:

Public health expenditure

Child health outcome

Economic development

FMOLS

West Africa.

Accepted: 19 November 2019

Published: 3 December 2019

\begin{abstract}
The study examines the long run relationship between public health expenditure and under-five mortality rate in 15 West African countries over the period of 1991-2015 with the use of panel fully modified least square (FMOLS). The empirical analysis is made up of both aggregate and disaggregated model. Based on the findings, long run relationship between per capita health expenditure and under-five mortality rate is confirmed. Further evidence indicates that public health expenditure has a significant impact on the rate of under-five mortality. Thus, it is revealed that an increase in health expenditure among West African countries would lead to a drastic reduction in infant mortality rate in the region. Furthermore, it is asserted that institutional quality, female literacy rate and immunization are central for reducing under-five mortality rate in the region. Hence, it is suggested that the quality of institutions, female literacy rate and immunizations which are often neglected in the literature should be accorded considerable priority in policy formulations. Also, governments of West African countries should increase the rate of health expenditure in their respective countries.
\end{abstract}

Funding: This study received no specific financial support Competing Interests: The authors declare that they have no competing interests.

Acknowledgement: Both authors are very grateful for the comments of anonymous referees, which have significantly enhanced the quality of the paper. We specially thank the editorial team of the journal for their exceptional support and guide. The usual disclaimer applies and views are solely expressed by the authors.

\section{Introduction}

Expenditure on healthcare is an indispensable tool for ensuring effective and efficient health care system performance. Appropriate health spending is required to accelerate the improvement in quantity and quality of different health care services, access to health care services, health output and health outcomes (Anyanwu \& Erhijakpor, 2012; Dauda, 2012). Health is regarded as a significant form of human capital, and there is a close relationship between the health level of the society and its economic development, resulting from the appreciable improvement in health outcomes (Bedir, 2016). Total health care expenditure, whether public or private, irrespective of the source would significantly improve the life expectancy at birth and infant mortality rate in Sub-Saharan Africa [SSA] (Novignon, Olakojo, \& Nonvignon, 2012). Similarly, among scholars, it is believed that an increase in health expenditure is expected to lead to an improvement in health outcomes (Amposah, 2008; Bloom \& Canning, 2008; Hartwig, 2009). However, the empirical literature is far from conclusion in this regard (Burnside \& Dollar, 1998; Filmer \& Pritchett, 1999; Musgrove, 1996).

Over the years, while statistical evidence confirms a steady trend for both improved health expenditure and health outcomes among industrialized countries, African has proved otherwise. For instance, among the European Union (EU) countries, between 1980 and 2015, average infant mortality fell from 16.04 to 3.71 deaths per 1000 live births; average life expectancy at birth rose from 76.4 to 83.9 and 69.5 to 78.5 years for female and male respectively. In EU countries, the total health expenditure (\% of GDP) rose to 10.4 in 2014 from 8.7 in 2000. Also, among the OECD countries, between 1995 and 2014, per capita health expenditure increased noticeably from $\$ 1876$ to $\$ 4701$, while life expectancy at birth increased from 70.4 to 83.9 for female and 72.4 to 78.5 for male during the same period (World Bank, 2017).

In contrast, regarding African countries, for example, between 2001 and 2015, government expenditure (\% of GDP) was 5.52 and 5.49 respectively, while it averaged 5.73 during the period indicating a slight $4 \%$ increase. According to Im, Pesaran, and Shin (2003) SSA witnessed the least health expenditure per capita 
compared to other regions of the world. For instance, per capita income in the region although increased from $\$ 2397.7$ (US) in 2000 to $\$ 3283.43$ (US) in 2011 , which further rose to $\$ 3439.9$ (US) in 2016 (Tandon \& Cashin, 2010). Nonetheless, it is still lower than the world average of $\$ 10,562$ (US) in year 2017. By and large, the low state of health expenditure in SSA has generated increased concern among researchers, since it could be responsible for the pervasive poor health outcomes in the region.

The ongoing academic debate within health expenditure and outcomes has been on the nexus between child health and health expenditure. Although there is a theoretical consensus on the linkage, empirical studies have yielded mixed conclusions. While some studies have established a positive impact of health expenditure on child mortality (Anand \& Ravallion, 1993; Bidani \& Ravallion, 1997; Kim \& Lane, 2013; Mehrara, 2011; Wagstaff et al., 2004). On the other hand, few studies have also reported that there is no relationship between health expenditure and child health (Dhrifi, 2018). The empirical evidence on health expenditure and child health are extensive in developed and most developing countries, whereas studies on the topical issue in relation to African countries, especially regarding ECOWAS countries, are scarce. Most of the studies on Africa concentrate more on SSA which failed to take into account the peculiarity of the ECOWAS region. Moreover, few studies available on health care expenditure and outcomes in SSA, where the world's poorest dwell, have shown divergent views both within and cross-country studies. Studies by Anyanwu and Erhijakpor (2012); Novignon et al. (2012); Bhalotra (2007); Abbas (2010); Mamy and Ngutunyi (2015) posit that there is a positive influence of health expenditure on child mortality. However, studies by Zakir and Wunnava (1999); Musgrove (1996); Burnside and Dollar (1998) give opposite assertion.

In SSA and other developing regions where resources are relatively scarce, health expenditure has received less attention in government budgets (World Health Report, 2010). Despite the meagre proportion of the gross domestic product (GDP) sets aside for health expenditure, the resources have not been efficiently utilized due to lack of strong and formidable policy formulations which is heavily relied on extensive research on the relationship between health expenditure and outcomes among these countries. Hence, this study will unravel the nexus between total health expenditure and child health outcomes in West African countries based on under-five mortality rate as proxy for infant health outcome. The variable has been widely used by scholars in the existing literature (Day \& Tousignant, 2005; Kaldewei, 2010; Novignon \& Lawanson, 2016).

The rest of the study is structured as follows: Section 2 centers on the review of literature. Section three gives detailed accounts of the methodological approach employed. Results and discussion are reported in section 4 , while the final section contains the concluding remarks.

\section{Literature Review}

Study by Or (2002) on OECD countries reveals a positive, albeit weak, relationship between public spending on health care and premature mortality. Analogously, a related research on 25 OECD countries by Ramesh and Sam (2007) using panel data approach with Fixed and Random Effect (RE) models which aimed at looking at the economic, institutional and social determinants of health outcomes concludes that the most important factor affecting infant mortality rate includes physician supply, followed by immunization. On the other hand, using the two-stage least squares in addition to the ordinary least squares techniques, Yaqub, Ojapinwa, and Yussuff (2010) examine the impact of public health spending on infant and under-five mortality as well as life expectancy. Due to the possibility of reverse causality, the result of the study shows that public health expenditure had negative effect on infant mortality and under-five mortality when governance indicators are included, but with a reversed sign without the governance indicators. The study argued that as the level of corruption goes down and the value of corruption perception index rises, there would be an improvement in health status, since infant mortality declines and life expectancy rises.

Nixon and Ulmann (2006) emphasized that although health expenditure and the number of physicians has made significant contribution to improvements in infant mortality, same has made relatively marginal contribution to the improvement in life expectancy in the EU countries over the period 1980-1995. Day and Day and Tousignant (2005), among others, investigated the relationship between health outcomes and health spending in Canada for the periods 1960-1997, 1950-1997 and 1926-1999, and commonly found that, although, some causal relationship between a measure of the health status of the population and real per capita health expenditure are statistically significant, these relationships are not very strong. The authors argued that the findings may be due to model misspecification or a reflection of high level of population growth and the smallness in the return to increases in health spending.

Crémieux, Ouellette, and Pilon (1999) studied the relationship between health indicators and total per capita spending on health in Canada, using pooled time-series and cross-section data for ten provinces over the period 1978-1992. The results revealed a strong relationship, despite insignificant differences in per capita health care spending and health outcomes across provinces. The findings clearly proved that lower health care spending in Canada is associated with lower life expectancies and higher infant mortality rates. A $10 \%$ reduction in health care spending is associated with an increase in infant mortality rates by $0.5 \%$ among males and $0.4 \%$ among females and life expectancies is reduced by 6 months for men and 3 months for women. Crémieux et al. (2005) estimates a similar model for the period 1981-1998, with per capital health spending being disaggregated into three categories; public spending on drugs, private spending on drugs, and non-drug 
health care spending. The results showed that improved infant mortality rates and life expectancies for both genders have resulted from increased public and private spending on drugs.

Issa and Ouattara (2005) employed data from 160 countries in analysing the effect of health expenditure on infant mortality rate. Health spending data was disaggregated into public and private expenditures. The authors argued that at low level of development, public expenditure is more effective in reducing infant mortality rate while private expenditure is effective as country develops. In another study, Schell et al. (2013) using linear regression model by separating countries according to their level of economic development, find that at any level of development, public health spending remains a non-significant contributor in reducing infant mortality rate.

Wagstaff. (2002b) treats government health expenditure as an exogenous variable and found out that government health spending does have a statistically significant (negative) impact and that the elasticity of under-five mortality with respect to government health spending is in the range of 0.08 to 0.15 . While Wagstaff. (2002b) does not account for endogeneity (due to reverse causality) of the government health spending term, the author suggests that the result is biased up (i.e. closer to zero than the true, larger in magnitude, negative value). However, when Wagstaff et al. (2004) treats government health spending as an endogenous variable, the elasticity with respect to government health spending is not statistically significant. In contrast to Wagstaff. (2002b); Wagstaff et al. (2004) Filmer and Pritchett (1999); Bokhari, Gai, and Gottret (2007) treats both variables (health expenditure and health outcomes) as endogenous. Using instrumental variables techniques of Generalized method of moments-Two stage Least Square (GMM-2SLS), the estimated result indicates that the elasticity of under-five mortality with respect to government expenditures ranges from -0.25 to -0.42 with a mean value of -0.33 . But for maternal mortality, the elasticity ranges from -0.42 to 0.52 with a mean value of -0.50. Thus, the results are consistent with Wagstaff. (2002b); Wagstaff et al. (2004) and Filmer and Pritchett (1999) which provides a much stronger evidence linking government health expenditures to health outcomes. Adam (2002a); Bokhari et al. (2007), however, argued that the effect of government health expenditure may be little or none if there are no complementary services, both within and outside the health sector (e.g lack of roads or transportation to hospitals and clinics, subsidized prices for health services, etc) to complement the increase in health expenditure.

Macinko, Guanais, and De Souza (2006), in their study which focused on the impact of family health program on infant mortality in Brazil, and using state level data from Brazil between 1990 and 2002, confirms the results of previous studies that there is no significant relationship between availability of physician and reductions in child mortality. Also, as observed by Grigoli and Kapsoli (2013), simply increasing public expenditure in the health sector, may not significantly affect health outcomes if the efficiency of this spending is low. Their findings suggest that African economies have the lowest efficiency. At current spending levels, they could boost life expectancy up to about five years if they followed best practices. A number of other studies have linked changes in mortality rates to the resource used at hospital, managed care, educational status of parents, females and children technological change (Cutler, 1995; Filmer. \& Pritchett, 1997; Geweke, Gowrisankaran, \& Town, 2003; Goldman \& Smith, 2002; Kessler \& McClellan, 2000; Lieras-Muney \& Glied, 2008; Mazunder, 2007; McClellan \& Noguchi, 1998).

Akinci, Hamidi, Suvankulov, and Akhmedjonov (2014) using pooled OLS, random effects, and HausmanTaylor IV model, found that both government and private spending on health care improves infant, child and maternal mortality in the Middle East and North Africa (MENA) region. In particular, a percentage increase in per capita government expenditures reduces the infant mortality rate by 8.6-9.5 deaths per 1000 live births, the under-five mortality by 10.3-12.1 deaths per 1000 live. Recent study by Kulkarni (2016) regarding emerging BRICS (Brazil, Russian federation, India, China and South Africa) countries, based on panel data fixed effects model, showed a positive relationship between health outcome and the GDP Per capita, Adult literacy rate, and Out of Pocket expenditure on health. The parameter estimates for public expenditure indicates a positively weak but significant elasticity, implying that higher public expenditure indicates higher infant mortality rate or lower health outcomes.

Mamy and Ngutunyi (2015), showed a strong negative linear correlation between under-five mortality and GDP per capital among Sub-Saharan African countries for the reviewed period (1990 - 2013). In addition, a strong negative linear correlation between under-five mortality rate and per capita health expenditure is found. The correlation between under-five mortality and percentage of GDP used as health expenditure also showed strong negative correlation for the period. Using linear dynamic panel data model in investigating this relationship, Odhiambo, Wambugu, and Kiriti-Ng'ang'a (2015) shows that public health expenditure is stronger in reducing under-five mortality; although it crowds out the relative effects of private health expenditure. The study further reveals that lowering corruption is essential in achieving low under-five mortality rates in Sub-Saharan Africa.

Anyanwu and Erhijakpor (2012) study on African countries reveals that infant and under-five mortality rates, per capita total health expenditure and per capita public health expenditure are negatively and significantly related. Specifically, in the Robust Ordinary Least Square method, a 10\% increase in per capita total health expenditure reduces the infant mortality rate by $22 \%$, while a $10 \%$ increase in per capita public health expenditure leads to a reduction of $21 \%$ in the infant mortality rate. Similarly, a $10 \%$ increase in per capita total health expenditure reduces under-five mortality by $21 \%$, while a similar $10 \%$ increase in per capita 
public health expenditure leads to a reduction of $25 \%$ in the under-five mortality rate. The findings are consistent with Bokhari et al. (2007); Issa and Ouattara (2005); Baldacci, Guin-Siu, and Mello (2003) and Or (2002) on the subject. Akinkugbe and Afeikhena (2006) also provides evidence that the effect of health care expenditure as a ratio of GDP on life expectancy, under-five mortality and infant mortality is positive and significant in Sub-Saharan Africa, Middle East and North Africa.

Regarding West Africa, in Nigeria, studies have also investigated the relationship between health expenditure and health outcomes. Awe and Ogungbenle (2009) in their study on Nigerian economy used annual time series data spanning through 1977 to 2005 explored the relationship within a Vector Autoregressive (VAR) model approach. Their study shows that there exist a casual linkage among social spending, human capital formation and output expansion in Nigeria. In another study by Ogungbenle, Olawumi, and Obasuyi (2013), results showed that positive relationship exists among gross domestic product (GDP), public health expenditure, and life expectancy in Nigeria. These results are in agreement with earlier studies of Anand and Ravallion (1993); Bidani and Ravallion (1997) and Gupta, Verhoven, and Tiongson (2003) who found a positive relationship between public expenditure on health and health status.

In addition, Asenso-Okyere (1995) study on public health financing in Ghana indicates the inadequacy of public expenditure and great inequality in rural and urban areas health care accessibility as the reasons for low health outcomes. Another study by Boachie and Ramu (2015), using OLS and Newey-West regression to examine the effect of public health expenditure on health outcomes (infant mortality) while real per capita income, literacy and female labour force participation rate were used as control variables, revealed that real per capita income was significant at $10 \%$ level after correcting for serial correlation, while public health spending, literacy rate and female labour force participation rate were significant at $5 \%$. The study further shows that public health expenditure exerts a strong negative influence on infant mortality; an increase by $1 \%$ on public health expenditure tends to reduce infant mortality by $0.11 \%$. The results however contradicts the findings of Berger and Messer (2002) that public health expenditure increases infant mortality. The study also shows that $1 \%$ increase in the literacy level has the potential of reducing infant mortality by $0.33 \%$. This findings confirms Grossman (1972) theory of demand for health that education increases the efficiency of health production (Micheal et al., 2014).

Yashim (2014) investigated the impact of health investments on child mortality in West Africa between 1992 and 2012. The study shows that an improvement in life expectancy at birth by $1 \%$ tends to reduce under five mortality by $3.98 \%$. Also, a percentage increase in real per capita income reduces under five mortality by $0.01 \%$. The results further affirm that increasing maternal literacy level, improved sanitary facilities by $1 \%$ could reduce infant mortality rate by $0.38 \%$ and $1.49 \%$ respectively. The variable of maternal mortality, improved water source, however showed a positive relationship with under five mortality, with a percentage increase in each of the variable leading to an increase in under five mortality by $3.72 \%$ and $0.68 \%$ respectively. However, empirical evidence from West African countries is scarce. Hence, this study specifically focuses on West Africa.

3. Methodology

3.1. Theoretical Framework

3.1.1. The Health Production Theory

The study employs the theory of production function as the theoretical framework, which depicts a relationship between physical outputs of a production process and physical inputs, i.e. factors of production. The practical application of production function is obtained by valuing the physical outputs and inputs by their prices. The economic value of physical outputs minus the economic value of physical inputs is the value addition generated by the production process. It is the maximum output that can be produced out of a given combination of inputs. The production function, therefore, describes a boundary or frontier representing the limit of output obtainable from each feasible combination of input.

A production function can be expressed in a functional form as:

$$
Q=f\left(X_{1}, X_{2}, X_{2}, \ldots \ldots \ldots \ldots \ldots, X_{n}\right)
$$

In Equation $1, Q$ is the quantity of output, and $X_{1}, X_{2}, X_{n}, \ldots \ldots \ldots \ldots \ldots, X_{n}$ are the quantities of factor inputs (such as capital, labour, land or raw materials. The function may be expressed linearly in the form;

$$
\mathrm{Q}=\mathrm{a}+\mathrm{b} X_{1}+\mathrm{c} X_{2}+\mathrm{d} X_{a}+
$$
$+\alpha X_{n}$

Equation 2 is the linear expression of Equation 1.

Applying this to empirical health modelling, health status depends on a number of factors, some of which can be influenced by the individual decisions. Hence, health can be produced. Similarly, health is also a consumption good because it enters into the utility function of the individuals.

Specifically, this work employs the demand for health care production function postulated by Grossman (1972). The model stated that the demand for health care is derived, and it is produced through a process of a production function. The model has been widely employed in empirical studies of health and health care (Abbas, 2010; Berger \& Messer, 2002; Kulkarni, 2016). According to Grossman (1972), there exists a relationship between health status and the economic and non-economic factors. In the model, individuals are 
assumed to inherit a stock of health capital $H_{0}$. Thereafter their health stock evolves according to the relationship as;

$$
H_{t}-H_{t-1}=I_{t-1}-\delta_{t-1} H_{t-1} \text { s }
$$

Where $H_{t}$ represents health stock at the beginning of period $t, I_{t-1}$ is gross investment during the period $t-1$ and $\delta_{t-1}$ is the rate of depreciation in operation during the same period. The equilibrium stock of health capital is defined by the condition as;

$$
\tau_{t}+\alpha_{t}=\left\{r+\delta_{t}-\pi_{t-1}\right\} \pi_{t},
$$

Where $\tau_{t}$ is the pecuniary benefit of health capital, $\alpha_{t}$ is the non-pecuniary marginal benefits, $r$ is the rate of interest, $\pi_{t}$ is the marginal cost of investment and $\pi_{t-1}$ is the percentage change in gross investment. Following Wagstaff (1993), we thus retain the inherently linear nature of the net investment identity of Equations 3 and 4 and adopt a linear specification of the demand-for-health Equation of the form;

$$
H_{t}=\beta X_{t}+u_{t} \text { o }
$$

Where $\mathrm{H}, \mathrm{X}$ and $\mathrm{u}$ are demand for health, determinants of demand for health and error term respectively. In its broad form, Equation 5 is specified as:

$$
H_{t}=\beta_{1} X_{1 t}+\beta_{2} X_{2 t}+u_{t} \text { o }
$$

Equation 6, expressed $H$ as any measure of health status like Life expectancy, infant mortality, $\mathbb{X}_{1 \mathrm{t}}$ is the non-economic factors like demographic (population below or above certain age group) and health service variables (like population doctor ratio, population hospital ratio etc.) and $\boldsymbol{X}_{2 \mathrm{t}}$ is the vector of economic factors like: (income per capita), social (education), environmental (urbanization). Although, Grossman (1972) presented the model at micro level, studies have employed this specification at macroeconomic level (Fayissa \& Gutema, 2014).

\subsection{Models Specification}

Following existing studies, child mortality is modelled to be a function of five factors. These are: per capita income, doctor's availability, total health expenditure per capita, immunization rates and female literacy. Mathematically, the production function explaining health outcomes in terms of under-five mortality rate (U5MR) in country $\mathrm{i}$ in year $\mathrm{t}$ is specified as follows in Equation 7:

$$
H_{\text {it }}=f\left(D O C_{\text {it }}, G D P P C_{i t} \text {, HEALTHPC it, IMMUN it }, F L R_{\text {it }}, I N S T Q_{\text {it }}\right)
$$

Econometrically, the model in Equation 7 is further specified as follows in Equation 8 and 9:

$$
\ln U 5 M R=\alpha_{0}+\alpha_{1} \ln F L R_{i t}+\alpha_{2} \ln D O C_{i t}+\alpha_{3} \ln G D P P C_{i t}+\alpha_{4} \ln H E A L T H P C_{i t}+\alpha_{5} \ln I M M U N_{i t}
$$

$$
\begin{aligned}
& +\alpha_{6} \ln I N S T Q_{i t}+\eta_{i}+w_{i t} \\
& w_{i t}=\mu_{i, t}+\varepsilon_{i t}
\end{aligned}
$$

To estimate the model, the study uses Fully Modified Ordinary Least Square (FMOLS). This technique produces reliable estimates, and offers a check for robustness of the results, even, if small sample size is involved in empirical investigations (Pedroni, 1996; Pedroni., 1999).

Where, $U 5 M R$ is under-five mortality rate; $D O C$ is the availability of doctor per patient; FLR is female literacy rate; GDPPC is Gross Domestic Product per capita; HEALTHPC is health expenditure per capita; INSTQ is the measure of institutional quality which is proxied by corruption index; $I M M U N$ is immunization (against measles). $\ln$ denotes natural logarithm; $i=$ country; $t=$ time. The error term in the above equation is $w_{\text {it }}$ with the assumption that $w_{\text {it }} \approx$ iid $\left(0, \sigma^{2}\right)$.

\subsection{Data and Sources}

This study uses a panel data set which includes 15 West African (ECOWAS) countries of Cape Verde, Senegal, Gambia, Guinea Bissau, Sierra Leonne, Liberia, Guinea, Cote D’ Ivoire, Ghana, Togo, Benin, Burkina Faso, Mali, Nigeria, Niger between 1991 and 2015. There were two reasons for selecting these countries. These countries form a group of low human development countries except for Cape Verde and Ghana that falls within medium human development (UNDP, 2015) and region in Africa with similar economic policies. Similarly, the whole countries agree to pursue both Millennium Development Goals (MDG) and the Sustainable Development Goals (MDG). The variables used for the analysis in terms of definition /or measurement with their respective sources are shown in Table 1.

\section{Empirical Results and Discussion \\ 4.1. Panel Unit Root Test}

Testing for the stationarity property of the variables has been described as fundamental in dynamic panel data model. In view of this, this study carries out an array of panel unit root tests in order to ensure the robustness and reliability of the estimates. The following panel unit root tests are adopted: Levin, Lin, and Chu (2002) test, Berger and Messer (2002) t-statistic, Im et al. (2003) ADF-Fisher and Philip Perron-Fisher chi-square. The summary of the results of these tests are presented in Table 2 and Table 3 . It is to be noted that both LLC and Breitung assume common unit root processes among cross-sectional units, while IPS, 
ADF-Fisher and PP-Fisher Chi-square assume individual unit root processes across cross-sectional unit. In running the tests, Schwarz Information Criterion (SIC) are used for selecting the lag length. The results of unit root tests with individual effect only are presented in Table 2 while Table 3 presents the unit root results of the individual effects with trends.

Table-1. Variable definition and sources.

\begin{tabular}{|c|c|c|}
\hline Variable & Definition/Measurement & Source \\
\hline Infant Mortality rate & This is expressed per 1,000 live birth & $\begin{array}{l}\text { World } \begin{array}{c}\text { Development } \\
\text { Indicators } \\
\text { (WDI), World Bank (2017). }\end{array} \\
\end{array}$ \\
\hline Gross domestic product per capita & $\begin{array}{l}\text { It is the gross domestic product of a } \\
\text { country divided by the population } \\
\text { using Purchasing Power Parity (PPP) } \\
\text { constant US } \$, 2005 \text { Prices }\end{array}$ & $\begin{array}{l}\text { World Development Indicators } \\
\text { (WDI), World Bank (2017). }\end{array}$ \\
\hline Female literacy Rate & $\begin{array}{l}\text { This is the rate of female that are } \\
\text { literate, measured by female enrolment } \\
\text { in secondary school (ages } 15 \text { and } \\
\text { above) per } 1,000\end{array}$ & $\begin{array}{l}\text { World Development Indicators } \\
\text { (WDI), World Bank (2017). }\end{array}$ \\
\hline Immunization & $\begin{array}{l}\text { Immunization against measles and } \\
\text { other diseases in percentage form }\end{array}$ & $\begin{array}{l}\text { World Development } \text { Indicators } \\
\text { (WDI), World Bank (2017). }\end{array}$ \\
\hline Institutional quality & $\begin{array}{l}\text { This is the governance development in } \\
\text { a country. It is proxied by corruption } \\
\text { index. It captures perceptions of the } \\
\text { extent to which public power is } \\
\text { exercised for private gain, including } \\
\text { both petty and grand forms of } \\
\text { corruption, as well as "capture" of the } \\
\text { state by elites and private interests. }\end{array}$ & $\begin{array}{l}\text { International Country Risk Guidance } \\
(2015)\end{array}$ \\
\hline Number of doctors & $\begin{array}{l}\text { This is defined as the number of } \\
\text { doctors or physicians per } 1,000 \text { people. }\end{array}$ & $\begin{array}{l}\text { World Development Indicators } \\
\text { (WDI), World Bank (2017). }\end{array}$ \\
\hline Health spending per capita & $\begin{array}{l}\text { This is the health spending per capita. } \\
\text { It captures the amount each person } \\
\text { spends on health in a year. }\end{array}$ & $\begin{array}{l}\text { World Development } \text { Indicators } \\
\text { (WDI), World Bank (2017). }\end{array}$ \\
\hline
\end{tabular}

As shown in Table 2 the result shows that the variables fail to attain stationarity at levels in most of these tests, the variables, however, were stationary at first difference based on the principles of Im et al. (2003) Wald test, Levin et al. (2002) test and Philip, Perron- Fisher's test (Choi, 2001) which are available for individual effects only. As a result, all the tests reject the null hypothesis that the variables contain unit root process at $1 \%$ and $5 \%$ levels of significance at first difference. The results establish that the variables portray the stationarity processes at first difference (that is, they are all integrated of order one [I (1)]. In addition, the results of the stationarity model on individual effects and linear trends are reported in Table 3 . This further establishes that all the variables are stationary at first difference.

Table-2. Panel unit root test (Individual Effect only).

\begin{tabular}{|c|c|c|c|c|}
\hline Variables & LLC & IPS & PP-Fisher & ADF-Fisher \\
\hline LINSTQ & -0.49210 & 0.79703 & 11.2951 & 11.4819 \\
\hline$\triangle \mathrm{LINSTQ}$ & $-7.52085^{* * * *}$ & 38.7474 **** & 45.9185**** & $38.7474^{*} * * *$ \\
\hline LINFMR & 3.85344 & 18.4210 & 25.4158 & 34.8207 \\
\hline$\Delta$ LINFMR & -3.98191 **** & $-0.79414^{* * * *}$ & $550.25 \mathrm{O}^{*} * * *$ & $208.946^{* * * *}$ \\
\hline LIMMUN & -1.12059 & -0.17285 & 25.0908 & 24.2875 \\
\hline$\triangle \mathrm{LIMMUN}$ & $-14.0637 * * *$ & $-12.8285^{* * * *}$ & $185.567^{*}$ **** & $197.617^{*} * *$ \\
\hline LHEALTHPC & 2.73853 & 5.16380 & 4.24151 & 5.17153 \\
\hline$\triangle$ LHEALTHPC & $-10.2534^{* * * *}$ & $-8.30150^{* * * *}$ & $117.027^{* * * * *}$ & $118.858^{* * * *}$ \\
\hline LGDPPC & 2.09364 & 4.14765 & 6.45392 & 6.89544 \\
\hline$\triangle \mathrm{LGDPPC}$ & $-13.0049^{* * * *}$ & $-10.7008^{* * * *}$ & $171.872^{* * * *}$ & $172.919^{* * * *}$ \\
\hline LFLR & $-1.59754^{*}$ & -0.13872 & 2.17265 & 2.03194 \\
\hline$\Delta$ LFLR & $-5.11148 * * *$ & - & $4.70516^{*}$ & $4.70516^{* *}$ \\
\hline LDOC & $-2.17616^{* *}$ & $-4.36628 * * *$ & $15.6274^{*}$ & $24.4966^{*}$ \\
\hline$\triangle \mathrm{LDOC}$ & $-10.3799^{* * * *}$ & - & $11.3756^{* * *}$ & 13.3038**** \\
\hline
\end{tabular}

Note: ***,** and * indicate $1 \%, 5 \%$ and $10 \%$ level of significance. $\Delta$ is the differenced operator.

LINSTQ $=\log$ of institutional quality; $\triangle \mathrm{LINSTQ}=$ differenced $\log$ of institutional quality; $\mathrm{LINFMR}=\log$ of infant mortality rate; $\triangle \mathrm{LINFMR}=$ differenced $\log$ of infant mortality rate; LIMMUN $=\log$ of Immunization; $\triangle$ LIMMUN $=$ differenced $\log$ of Immunization; LHEALTHPC $=\log$ Health Expenditure per capita; $\triangle$ LHEALTHPC $=$ differenced $\log$ Health Expenditure per capita; LGDPPC $=\log$ of GDP per capita $\triangle \mathrm{LGDPPC}=$ differenced $\log$ of GDP per capita; LFLR $=\log$ of Female Literacy Rate; $\triangle \mathrm{LFLR}=$ differenced $\log$ of Female Literacy Rate; LDOC $=\log$ of Number of Medical Doctors; $\Delta \mathrm{LDOC}=$ differenced $\log$ of Number of Medical Doctors. 
Table-3. Panel unit root test (Individual Effect and Linear Trends).

\begin{tabular}{c|c|c|c|c|c}
\hline Variables & LLC & Breitung & IPS & PP-Fisher & ADF-Fisher \\
\hline LINSTQ & $-4.32075^{* * *}$ & -0.28495 & 0.09909 & 22.8069 & 19.5141 \\
\hline$\Delta$ LINSTQ & $-8.78194 * * *$ & $-4.2523^{* * *}$ & -1.15647 & $39.8697^{* *}$ & $81.9473^{* * *}$ \\
\hline LINFMR & 1.80712 & 9.89461 & 7.04202 & 12.6080 & 11.7740 \\
\hline$\Delta$ INFMR & $-10.2104 * * *$ & 13.0743 & $-4.01759^{* * *}$ & $123.592^{* * *}$ & $85.2090^{* * *}$ \\
\hline LIMMUN & -0.98587 & -1.99223 & -0.69456 & 27.3342 & 26.9773 \\
\hline$\Delta$ LIMMUN & $-12.3402^{* * *}$ & $7.73034^{* * *}$ & $-10.5690^{* * *}$ & $189.368^{* * *}$ & $141.549^{* * *}$ \\
\hline LHEALTHPC & -0.22706 & 0.28838 & 1.30111 & 17.6361 & 17.5719 \\
\hline$\Delta$ LHEALTHPC & $-8.91104^{* * *}$ & $-6.82638^{* * *}$ & $-6.30442^{* * *}$ & $88.2572^{* * *}$ & $91.2058^{* * *}$ \\
\hline LGDPPC & $-3.03060^{* *}$ & 0.17301 & -0.23094 & $41.2836^{*}$ & 37.8172 \\
\hline$\Delta$ LGDPPC & $-12.0974^{* * *}$ & $-7.39978^{* * *}$ & $-6.97011^{* * *}$ & $153.380^{* * *}$ & $137.005^{* * *}$ \\
\hline LFLR & $-1.77083^{* *}$ & -1.22554 & 0.17069 & 2.90770 & 1.04198 \\
\hline$\Delta$ LFLR & $-2.34632^{* * *}$ & $-6.43583^{* * *}$ & $3.76542^{* * *}$ & $7.43743^{* * *}$ & $3.43243^{* *}$ \\
\hline LDOC & $-63.8053^{* * *}$ & $3.4 \mathrm{E}-13^{*}$ & -1.08151 & 7.83040 & 14.3252 \\
\hline$\Delta$ LDOC & $-93.8053^{* * *}$ & $6.4 \mathrm{E}-17^{* * *}$ & $-4.08741^{* * *}$ & $9.83534^{* * *}$ & $26.5724^{* * *}$ \\
\hline
\end{tabular}

Note: $* * * * *$ and $*$ indicate $1 \%, 5 \%$ and $10 \%$ level of significance. $\Delta$ is the differenced operator.

LINSTQ $=\log$ of institutional quality; $\triangle \mathrm{LINSTO}=$ differenced $\log$ of institutional quality; LINFMR $=\log$ of infant mortality rate; $\triangle$ LINFMR= differenced $\log$ of infant mortality rate; LIMMUN= log of Immunization; $\Delta$ LIMMUN $=$ differenced $\log$ of Immunization; LHEALTHPC $=\log$ Health Expenditure per capita; $\triangle$ LHEALTHPC $=$ differenced $\log$ Health Expenditure per capita; $L G D P P C=\log$ of GDP per capita; $\triangle \mathrm{LGDPPC}=$ differenced $\log$ of GDP per capita; LFLR $=\log$ of Female Literacy Rate; $\triangle \mathrm{LFLR}=$ differenced $\log$ of Female Literacy Rate; $\mathrm{LDOC}=\log$ of Number of Medical Doctors; $\Delta \mathrm{LDOC}=$ differenced $\log$ of Number of Medical Doctors.

4.2. Panel Cointegration Test

In order to investigate the existence of the long run relationship among the variables in the model, this study employs Pedroni technique of panel cointegration. As shown in Table 4, six out of the seven statistic tests indicate that long run relationship exists among the variables at $1 \%$ and $5 \%$, while a test shows that there is a long run relationship among the variables at $10 \%$. It can therefore be confidently concluded that there exists a long run relationship among the variables in the model.

\begin{tabular}{l|c}
\multicolumn{2}{c}{ Table-4. Cointegration test. } \\
\hline Statistic & Coefficients and Probability \\
\hline Panel v-Statistic & -1214.187 \\
\hline Panel rho-Statistic & $-0.063380^{* *}$ \\
\hline Panel PP-Statistic & $-2.892361^{* * *}$ \\
\hline Panel ADF-Statistic & $-2.893687^{* * * *}$ \\
\hline Group rho-Statistic & $1.213152^{*}$ \\
\hline Group PP-Statistic & $-1.959964^{* *}$ \\
\hline Group ADF-Statistic & $-1.895658^{* *}$ \\
\hline
\end{tabular}

\subsection{Descriptive Statistics and Correlation Analysis}

Apart from the main model, further disaggregation is made by the study on the model which takes care of highly corrupt countries. Corruption Perception Index (CPI) published by International Risk Guide, 2015 was used for the country selection. Out of the 167 countries that participated in 2015, the least corrupt country of Demark is rated 1, while the most corrupt country of Somalia is rated 167 in the index. All the ECOWAS countries participated in the rating; hence, the index gives a robust analysis for this study. In order to identify the most corrupt countries, the study uses the benchmark of 95 score. Hence, all ECOWAS countries rated 95 and above are selected as the most corrupt countries used in the disaggregated model. Nine countries of Cote d'Ivoire, Mali, Niger, Togo, Guinea, Guinea Bissau, Gambia, Serra Leone and Nigeria fall into this category. Based on theoretical expectation, the possibility of diverting government expenditure on child health is very high among these countries.

Table-5. Descriptive statistics of the variables (aggregate Model).

\begin{tabular}{c|c|c|c|c}
\hline Variables & Mean & Maximum & Minimum & Std. Dev. \\
\hline INSTQ & 2.995146 & 4.50000 & 2.000000 & 0.729166 \\
\hline UND5MR & 139.8141 & 241.1000 & 52.50000 & 25.13980 \\
\hline IMMUN & 67.87412 & 99.00000 & 0.171000 & 23.02367 \\
\hline HEALTHPC & 33.95275 & 174.9844 & 4.501221 & 29.50824 \\
\hline GDPPC & 14645.09 & 612204.6 & 130.9127 & 84194.15 \\
\hline FLR & 29.29791 & 80.49622 & 6.579713 & 18.60990 \\
\hline DOC & 0.088367 & 0.572000 & 0.014000 & 0.090077 \\
\hline
\end{tabular}

Note: Where GDPPC $=$ GDP per capita; INSTQ=Institutional Quality; FLR $=\log$ of Female Literacy Rate; HEALTHPC $=$ Health Expenditure per capita; IMMUN $=$ Number of Immunized Children per thousand; DOC $=$ No of Doctors; UND5MR $=$ Under-Five Mortality Rate. 
In order to offer comprehensive information on the key variables and to unravel the detail needed to give background hints on their characteristics, the study provides two tables on descriptive analysis. Table 5 provides insights on the overall descriptive statistics of the aggregate model, while Table 6 is basically built for corrupt countries robust estimates. Table 7 shows the correlation coefficients between the variables. The table reveals a low degree of correlation between variables used in the aggregated model is low.

Table-6. Descriptive statistics of the variables (disaggregated model using institutional quality).

\begin{tabular}{c|c|c|c|c}
\hline Variables & Mean & Maximum & Minimum & Std. Dev. \\
\hline$I N S T Q$ & 2.461538 & 3.500000 & 2.000000 & 0.505755 \\
\hline UND5MR & 143.1913 & 241.1000 & 80.80000 & 28.32786 \\
\hline$I M M U N$ & 63.53911 & 98.00000 & 0.171000 & 25.47187 \\
\hline$H E A L T H P C$ & 29.34505 & 95.83287 & 8.653538 & 18.99628 \\
\hline GDPPC & 28238.44 & 612204.6 & 156.5919 & 117179.6 \\
\hline FLR & 24.41674 & 80.49622 & 6.579713 & 14.20729 \\
\hline DOC & 0.088236 & 0.572000 & 0.016000 & 0.093917 \\
\hline
\end{tabular}

Note: Where GDPPC $=$ GDP per capita; INSTQ=Institutional Quality; FLR $=$ log of Female Literacy Rate; HEALTHPC $=$ Health Expenditure per capita; IMMUN $=$ Number of Immunized Children per thousand; DOC $=$ No of Doctors; UND5MR= Under-Five Mortality Rate.

Table-7. Correlation matrix of the aggregate model

\begin{tabular}{c|c|c|c|c|c|c|c}
\hline Variables & LFLR & LDOC & LGDPPC & LHEALTHPC & LIMMUN & LINSTQ & LUND5MR \\
\hline LFLR & 1.000000 & & & & & & \\
\hline LDOC & 0.138481 & 1.000000 & & & & & \\
\hline LGDPPC & -0.038038 & 0.537185 & 1.000000 & & & & \\
\hline LHEALTHPC & 0.418675 & 0.350830 & 0.620950 & 1.000000 & & & \\
\hline LIMMUN & 0.494905 & -0.206257 & -0.583787 & 0.110520 & 1.000000 & & \\
\hline LINSTQ & 0.147997 & 0.125416 & 0.022697 & 0.299618 & 0.167225 & 1.000000 & \\
\hline LUND 5 MR & -0.167989 & 0.013378 & -0.138444 & -0.178344 & -0.120797 & 0.020976 & 1.000000 \\
\hline
\end{tabular}

Note: Where LGDPPC $=\log$ of GDP per capita; LINSTQ $=\log$ of Institutional Quality; LFLR $=\log$ of Female Literacy Rate; LHEALTHPC $=\log$ of Health Expenditure per capita; LIMMUN $=\log$ of Number of Immunized Children per thousand; LDOC $=\log$ of Number of Doctors; LUND 5 MR $=\log$ of Under-Five Mortality Rate.

Table-8. Correlation matrix of the disaggregated model (weak institutional quality).

\begin{tabular}{c|c|c|c|c|c|c|c}
\multicolumn{7}{c}{ Table-8. Correlation matrix of the disaggregated model (weak institutional quality). } \\
\hline Variables & LFLR & LDOC & LGDPPC & LHEALTHPC & LIMMUN & LINSTQ & LUND5MR \\
\hline LFLR & 1.000000 & & & & & & \\
\hline LDOC & -0.254246 & 1.000000 & & & & & \\
\hline LGDPPC & -0.394594 & 0.444657 & 1.000000 & & & & \\
\hline LHEALTHPC & 0.134671 & -0.058626 & 0.491066 & 1.000000 & & & \\
\hline LIMMUN & 0.506732 & -0.434618 & -0.828920 & -0.146096 & 1.000000 & & \\
\hline LINSTQ & -0.284214 & -0.178636 & -0.204196 & 0.102709 & -0.006177 & 1.000000 & \\
\hline LUND $5 M R$ & -0.140884 & 0.025241 & -0.091650 & -0.090523 & -0.087771 & 0.144000 & 1.000000 \\
\hline
\end{tabular}

Note: Where LGDPPC $=\log$ of GDP per capita; LINSTQ $=\log$ of Institutional Quality; LFLR $=\log$ of Female Literacy Rate; LHEALTHPC $=\log$ of Health Expenditure per capita; LIMMUN $=\log$ of Number of Immunized Children per thousand; LDOC $=\log$ of Number of Doctors; LUND5MR $=\log$ of UnderFive Mortality Rate.

\subsection{Panel Fully Modified Least Square (FMOLS) Estimates}

Given that FMOLS takes care of the issue of endogeneity in the model by adding the leads and lags to the model, and more efficient than OLS in handling multicollinearity and autocorrelation issues in empirical model, the estimates are based on panel FMOLS developed by Pedroni (1996). In the analysis Child health outcome is captured by under-five child mortality. In Table 8 estimated results show that four out of the five variables investigated in the model are statistically significant, and are consistent with a prior expectation. Based on the results, an increase in the quantity and availability of medical doctors reduces under-five infant mortality by 0.02 . This is expected when the low levels of medical personnel in African countries is taken into consideration. Hence, the governments of these countries are encouraged to employ more medical doctors in order to reduce the under-five mortality. Similarly, increasing per capita health expenditure also reduces child mortality. Accordingly, a unit increase in the per capita expenditure reduces under-five mortality by 0.08. These findings corroborate the conclusion of Odhiambo et al. (2015) in that public health expenditure is found stronger in reducing under-five mortality, although it crowds out the relative impacts of private health expenditure. The implication of this is that stakeholders from ECOWAS members' countries should encourage governments in respective countries to increase allocations to health sector, as the resultant outcome would be a significant reduction in under-five mortality.

Furthermore, two determinants of under-five child mortality often neglected in the empirical literature are also considered in this study (immunization and institutional quality). Results show that both variables are, however, important for the determinants of under-five child mortality in West African countries. For instance, 
a unit increase in the number of immunized children in ECOWAS countries reduces under-five children mortality by 0.06 . In fact, this variable is the most significant factor determining the under-five child mortality in West African countries. Thus, the governments of these countries are advised to increase their health spending and consequently allocations for immunizations for under-five children. Similarly, the donor organizations are encouraged to increase their donations for immunization as this is an effective means of addressing under-five mortality.

Regarding institutional effect, institutional quality (corruption index) is also found to be statistically significant. Following the estimated results, a unit improvement in the level of institutions reduces child mortality by 0.52. This confirms the argument of the institutional school that institutions matter. Hence, it could be suggested that an improvement of the quality of institutions might reduce corruption, and increasing transparency which would lead to sound management of per capita health spending, and thus stimulates better health outcome. Analogously, Table 9 (aggregated model) and Table 10 (disaggregated model) also reveals the significant effect of these variables on under-five child mortality in West Africa.

Table-9. Panel fully modified least square (FMOLS) estimation — aggregate model

\begin{tabular}{c|c|c}
\hline Dependent variable: LUND5MR & Estimates & T-statistic \\
\hline Variables & $-0.094479^{* *}$ & -1.739344 \\
\hline LFLR & $-0.017850^{* *}$ & -0.698567 \\
\hline LDOC & $-0.080524^{* * *}$ & -3.244425 \\
\hline LGDPPC & $-0.133813^{*} * *$ & -7.402831 \\
\hline LHEALTHPC & $-0.055306^{* *}$ & -2.305346 \\
\hline LIMMUN & $-0.518769^{*} *$ & -7.430750 \\
\hline LINSTQ &
\end{tabular}

Note: Normality (Prob.) 0.000374 R-squared 0.597314 Adjusted. R-square 0.571140

****, ** indicates $1 \%$ and $5 \%$ level of significance.

Where, LGDPPC $=\log$ of GDP per capita; LINSTQ $=\log$ of Institutional Quality; LFLR $=\log$ of Female Literacy Rate;

LHEALTHPC $=\log$ of Health Expenditure per capita; LIMMUN $=\log$ of Number of Immunized Children per

thousand; LDOC $=\log$ of Number of Doctors; LUND5MR $=\log$ of Under-Five Mortality Rate.

Table-10. Panel fully modified least square (FMOLS) estimation- disaggregated model (Weak Institutional Ouality).

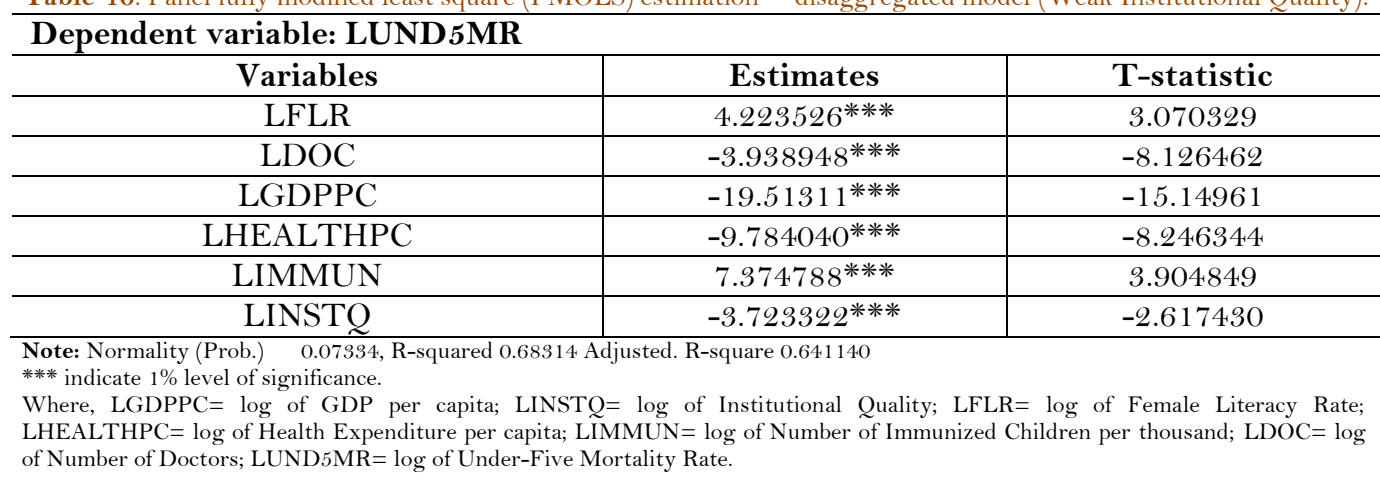

\section{Concluding Remarks}

Given the high rate of infant mortality in developing countries, researchers have developed keen interest as to how there could be a drastic reduction in the trend of infant mortality in these countries. In practice, some aspects of socioeconomic indicators may be used in empirical estimation, either because they are viewed to have direct effect or data on these indicators are more readily available than the corresponding proximate variables. The study identifies the actual variables to be used with reference to the existing empirical work. Specifically, through the use of panel fully modified least square (FMOLS), the existence of long run relationship between public health expenditure and under-five mortality rate in West African countries is examined over the period of 1991-2015. In order to establish the importance of institutional quality, the empirical analysis is made up of both aggregate and disaggregated model. (i.e a general analysis was carried out on all the West African countries, and another analysis was carried out on the countries with an evidence of weak institution). The institutional quality argument is rooted in the theoretical submission of the institutional school with the submission that the quality of institutions strongly influences macroeconomic variables (North, 1990).

Based on the findings, long run relationship between all the socioeconomic indicators used and under-five mortality rate is confirmed. Further evidence indicates that public health expenditure has a significant impact on the rate of under-five mortality. The same is established for the disaggregated model of institutional quality. It is affirmed that all the indicators are crucial for explaining child mortality rates in West African countries. Thus, it is revealed that an increase in health expenditure among West African countries would lead to a drastic reduction in infant mortality rate in the region. However, total health expenditure does not show a considerable improvement during the period under study, this could be responsible for the persistent poor 
child health outcome across West African countries. In addition, it is asserted that institutional quality, female literacy rate and immunization are central for reducing under-five mortality rate in the region. Hence, it is suggested that the quality of institutions, female literacy rate and immunizations, which are often neglected in the literature should be accorded considerable priority in policy formulations. Finally, governments of West African countries should increase the rate of health expenditure in their respective countries.

\section{References}

Abbas, F. (2010). Public health sector expenditures, health status and their role in development of Pakistan. Cuvillier Verlag, Inhaberin Annette Jentzsch-Cuvillier, Nonnenstieg 8, 37075 Gottingen, Germany.

Adam, W. (2002a). Health Spending and aid as escape routes from the vicious circle of poverty and Health. Paper presented at the Prepared for British Association for the Advancement of Science Meeting, 2002.

Akinci, F., Hamidi, S., Suvankulov, F., \& Akhmedjonov, A. (2014). Examining the impact of health care expenditures on health outcomes in the middle East and N. Africa. Journal of Health Care Finance, 41(1), 1-23.

Akinkugbe, O., \& Afeikhena, J. (2006). Public health care spending as a determinant of health status: A panel data analysis for SSA and MENA. Applied Macroeconomics and Economic Development.

Amposah, K. (2008). Financing of health care in low income countries (LICs) addressing the funding gap in Southern Sudan. Paper presented at the Government of Southern Sudan Ministry of Health, First DCP 2 Workshop, Juba, Southern Sudan, June 9th -11 th, 2008

Anand, S., \& Ravallion, M. (1993). Human development in poor countries: On the role of private incomes and public services. Journal of Economic Perspectives, 7(1), 133-150. Available at: https://doi.org/10.1257/jep.7.1.133.

Anyanwu, J. C., \& Erhijakpor, A. E. O. (2012). Health expenditures and health outcomes in Africa. International Monetary Fund.

Asenso-Okyere, W. K. (1995). Financing health care in Ghana. Health Economics and Financing, 16(1), 400-433.

Awe, A. A., \& Ogungbenle, S. (2009). Social spending, human capital formation and output expansion in Nigeria economy: 1977-2005. International Journal of Administrative Studies and Research, 1(1 1), 27-53.

Baldacci, E., Guin-Siu, M. T., \& Mello, L. D. (2003). More on the effectiveness of public spending on health care and education: A covariance structure model. Journal of International Development: The Journal of the Development Studies Association, 15(6), 709-725.

Bedir, S. (2016). Healthcare expenditure and economic growth in developing countries. Advances in Economics and Business, 4(2), 76-86. Available at: https://doi.org/10.13189/aeb.2016.040202.

Berger, M. C., \& Messer, J. (2002). Public financing of health expenditures, insurance, and health outcomes. Applied Economics, 34(17), 2105-2113. Available at: https://doi.org/10.1080/00036840210135665.

Bhalotra, S. (2007). Spending to save? State health expenditure and infant mortality in India. Health Economics, 16(9), $911-$ 928. Available at: https://doi.org/10.1002/hec.1260.

Bidani, B., \& Ravallion, M. (1997). Decomposing social indicators using distributional data. Journal of Econometrics, 77, 125139. Available at: https://doi.org/10.1016/s0304-4076(95)01809-3.

Bloom, D. E., \& Canning, D. (2008). Population health and economic growth. Working Paper No.24, Commission on Growth and Development, The World Bank, Washington DC.

Boachie, M. K., \& Ramu, K. (2015). Public health expenditure and health status in Ghana. Munich Personal Re PEc Archive. Retrieved from: https://mpra.ub.uni-muenchen.de/66371/MPRA paper no. 66371.

Bokhari, F. A., Gai, Y., \& Gottret, P. (2007). Government health expenditures and health outcomes. Health Economics, 16(3), 257-273. Available at: https://doi.org/10.1002/hec.1157.

Burnside, D., \& Dollar, H. (1998). Aid, the Incentive regime and poverty reduction. Washington DC: The World Bank.

Choi, I. (2001). Unit root tests for cross-sectionally correlated panels, mimeographed: Kukmin University.

Crémieux, P.-Y., Meilleur, M.-C., Ouellette, P., Petit, P., Zelder, M., \& Potvin, K. (2005). Public and private pharmaceutical spending as determinants of health outcomes in Canada. Health Economics, 14(2), 107-1 16

Crémieux, P.-Y., Ouellette, P., \& Pilon, C. (1999). Health care spending as determinants of health outcomes. Health Economics, 8(7), 627-639.

Cutler, D. M. (1995). The incidence of adverse medical outcomes under prospective payment. Econometrica, 63(1), 29-50.

Dauda, M. I. (2012). Government health expenditure. Health outcomes and economic growth in selected Sub-Sahara African countries (1995-2009), department of economics, Obafemi Awolowo University, Ile-Ife. P.hd. Thesis Unpublished, Obafeemi Awolowo University, Ile- Ife.

Day, K., \& Tousignant, J. (2005). Health spending, health outcome and per capita income in Canada: A dynamic analysis. Working Paper 2005 - 07. June 2005.

Dhrifi, A. (2018). Health-care expenditures, economic growth and infant mortality: Evidence from developed and developing countries. CEPAL Reviere, 125, 69-91.

Fayissa, B., \& Gutema, P. (2014). The determinants of health status in Sub-Saharan Africa (SSA). The American Economist, 49(2), 60-66.

Filmer, D., \& Pritchett, L. (1999). The impact of public spending on health: Does money matter? Social Science \& Medicine, 49(10), 1309-1323. Available at: https://doi.org/10.1016/s0277-9536(99)00150-1.

Filmer., D., \& Pritchett, L. (1997). Child mortality and public spending on health: How much does money matter? Policy Research Working, Washington, DC: World Bank. No.1864.

Geweke, J., Gowrisankaran, G., \& Town, R. J. (2003). Bayesian inference for hospital quality in a selection model. Econometrica, 71(4), 1215-1238. Available at: https://doi.org/10.1111/1468-0262.00444.

Goldman, D. P., \& Smith, J. P. (2002). Can patient self-management help explain the SES health gradient? Proceedings of the National Academy of Sciences, 99(16), 10929-10934. Available at: https://doi.org/10.1073/pnas.162086599.

Grigoli, F., \& Kapsoli, J. (2013). Waste not, want not: The efficiency of health expenditure in emerging and developing economies. IMF Working Paper. WP/13/187. 
Grossman, M. (1972). On the concept of health capital and the demand for health. Journal of Political Economy, 80(2), 223255. Available at: https://doi.org/10.1086/259880.

Gupta, S., Verhoven, M., \& Tiongson, E. (2003). The effectiveness of government spending on education and health care in developing and transition economics. European Journal of Political Economy.

Hartwig, J. (2009). Is health capital formation good for long term economic growth? - panel granger-causality evidences for OECD countries. Journal of Macroeconomics, Elsevier, Inc in Press.

Im, K. S., Pesaran, M. H., \& Shin, Y. (2003). Testing for unit roots in heterogeneous panels. Journal of Econometrics, 115(1), 53-74. Available at: https://doi.org/10.1016/s0304-4076(03)00092-7.

International Country Risk Guidance. (2015). Political risk services guide. Retrieved from: https:// info.worldbank.org.> governance $>$ wgi $>$ home $>$ download.

Issa, H., \& Ouattara, B. (2005). The effect of private and public health expenditure on infant mortality rates: Does the level of development matters? Singleton Park: University of wales Swansea.

Kaldewei, C. (2010). Determinants of infant and under-five mortality - the case of Jordan, technical note, february 2010.

Kessler, D. P., \& McClellan, M. B. (2000). Is hospital competition socially wasteful? The Quarterly Journal of Economics, 115(2), 577-615. Available at: https://doi.org/10.1162/003355300554863.

Kim, T. K., \& Lane, S. R. (2013). Government health expenditure and public health outcomes: A comparative study among 17 countries and implications for US health care reform. American International Journal of Contemporary Research, 3(9), 8-13.

Kulkarni, L. (2016). Health inputs, health outcomes and public health expenditure: Evidence from the BRICS countries. International Journal of Applied Economic, 31(1), 72-84.

Levin, A., Lin, C.-F., \& Chu, C.-S. J. (2002). Unit root tests in panel data: Asymptotic and finite-sample properties. Journal of Econometrics, 108(1), 1-24. Available at: https://doi.org/10.1016/s0304-4076(01)00098-7.

Lieras-Muney, A., \& Glied, S. (2008). Health inequality, education and medical innovation, demography 2008. 45(3), 741761 .

Macinko, J., Guanais, F. C., \& De Souza, M. D. F. M. (2006). Evaluation of the impact of the family health program on infant mortality in Brazil, 1990-2002. Journal of Epidemiology \& Community Health, 60(1), 13-19.

Mamy, A., Xu, H., \& Ngutunyi, M. (2015). Re-examining the correlation of under-five mortality to economy and health expenditure indicators in Sub-Saharan African countries (1990-2013). International Journal of Advanced Physiology and Allied Sciences, 2(1), 53-68.

Mazunder, B. (2007). How did schooling laws improve long-term health and lower mortality. Working Paper Series WP06-03, Chicago: Federal Reserve Bank of Chicago; 2007.

McClellan, M., \& Noguchi, H. (1998). Technological change in heart-disease treatment. Does high tech mean low value? The American Economic Review, 88(2), 90-96.

Mehrara, M. (2011). Health expenditure and economic growth: An ARDL approach for the case of Iran. Journal of Economics and Behavioral Studies, 3(4), 249-256.

Micheal, K. B., Mensah, I. O., Sobiesuo, P., Immurana, M., Iddrisu, A.-A., \& Kyei-Brobbey, I. (2014). Determinants of public health expenditure in Ghana: A cointegration analysis. J Behav Econ Finance Entrep Account Transp, 2(2), $35-40$.

Musgrove, P. (1996). Public and private roles in health: Theory and financing patterns. Health, Nutrition and Population (HNP) Discussion Paper.The International Bank for Reconstruction and Development/World Bank. Washington, DC. 20433.

Nixon, J., \& Ulmann, P. (2006). The relationship between health care expenditure and health outcomes. The European Journal of Health Economics, 7(1), 7-18. Available at: https://doi.org/10.1007/s 10198-005-0336-8.

North, D. C. (1990). Institutions, Institutional change and economic performance. New York: Cambridge University Press.

Novignon, J., \& Lawanson, A. O. (2016). Health expenditure and child health outcomes in Sub-Saharan Africa. African Review of Economics and Finance.

Novignon, J., Olakojo, S., \& Nonvignon, J. (2012). The effects of public and private health care expenditure on health status in Sub-Saharan Africa: New evidence from panel data analysis. Health Economics Review, Springer, 2(1), 1-8.

Odhiambo, S. A., Wambugu, A., \& Kiriti-Ng'ang'a, T. (2015). Effect of health expenditure on child health in Sub-Saharan Africa: Governance perspective. Journal of Economics and sustainable Development, 6(8), 43-65.

Ogungbenle, S., Olawumi, O., \& Obasuyi, F. (2013). Life expectancy, public health spending and economic growth in Nigeria: A vector autoregressive (VAR) model. European Scientific Journal, 9(19), 1857-7881.

Or, Z. (2002). Exploring the effects of health care on mortality across OECD Countries, OECD labour market and social policy occasional papers. OECD Publishing. No. 46.

Pedroni, P. (1996). Fully modified OLS for heterogeneous cointegrated panels and the case of purchasing power parity. Manuscript, Department of Economics, Indiana University, 1-45.

Pedroni., P. (1999). Purchasing power parity tests in cointegrated panels. Working Paper Department of Economics, Indiana University.

Ramesh, M., \& Sam, M. (2007). An assessment of OECD health care system using panel data analysis. MPRA Paper No. 6122.

Schell, S. F., Luke, D. A., Schooley, M. W., Elliott, M. B., Herbers, S. H., Mueller, B. N., \& Bunger, A. C. (2013). Public health program capacity for sustainability: A new framework. Schell et al.Implementation Science 2013, 8(1), 15-15.

Tandon, A., \& Cashin, C. (2010). Assesing public expenditure on health from a fiscal space perspective. Health, nutrition and population (HNP) discussion paper. Washington DC: The World Bank.

UNDP. (2015). Human development Report 2015: Work for human development. New York: United Nations Development Programme.

Wagstaff, A. (1993). The demand for health: An empirical reformulation of the grossman model. Health Economics, 2(2), 189-198. Available at: https://doi.org/10.1002/hec.4730020211. 
Wagstaff, A., Bustreo, F., Bryce, J., Claeson, M., Who-World, B. C. H., \& Poverty, W. G. (2004). Child health: Reaching the poor. American Journal of Public Health, 94(5), 726-736.

Wagstaff., A. (2002b). Intersectoral synergies and the health MDG's: Preliminary cross-country findings. Corroboration and Policy Simulations, Prepared for Development Committee on Accelerating Progress towards the HNP MDGs.

World Bank. (2017). World development indicator 2017. Washington, D.C: The World Bank.

World Health Report. (2010). World health organisation. Paper presented at the Keynote Address at the International Ministerial Conference on Health System Financing. Berlin, Germany 22 November 2010.

Yaqub, J. O., Ojapinwa, \& Yussuff, R. O. (2010). Public health expenditure and health outcome in Nigeria. The impact of governance. European Scientific Journal, 8(13), 1857-7881.

Yashim, R. R. (2014). The impact of health investment on child mortality in West Africa (1992-2012) The department of Economics and Development Studies. Covenant University, Otta, Ogun State, Nigeria. Unpublished Thesis.

Zakir, M., \& Wunnava, P. V. (1999). Factors affecting infant mortality rates: Evidence from cross-sectional data. Applied Economics Letters, 6(5), 271-273. Available at: https://doi.org/10.1080/135048599353203. 